\title{
Validation of Siriraj Stroke Score in southeast Nigeria
}

This article was published in the following Dove Press journal:

International Journal of General Medicine

23 October 2015

Number of times this article has been viewed

Innocent Ijezie Chukwuonye'

Kenneth Arinze Ohagwu ${ }^{2}$

Enoch Ogbonnaya Uche ${ }^{3,4}$

Abali Chuku ${ }^{5}$

Rowland Ihezuo Nwanke ${ }^{2}$

Christopher Chukwuemeka

Ohagwu $^{6}$

Ignatius $U$ Ezeani ${ }^{7}$

Collins Ogbonna Nwabuko ${ }^{8}$

Martin Anazodo Nnoli ${ }^{9}$

Efosa Oviasu 4,10

Okechukwu Samuel Ogah4,11

'Division of Nephrology, ${ }^{2}$ Division of Neurology, Department of Internal

Medicine, Federal Medical Centre, Umuahia,

Nigeria; ${ }^{3}$ Division of Neurosurgery,

Department of Surgery, University of

Nigeria Teaching Hospital, Enugu, Nigeria;

${ }^{4}$ Federal Medical Centre, Umuahia,

Nigeria; ${ }^{5}$ Department of Ophthalmology,

Federal Medical Centre, Umuahia,

Nigeria; ${ }^{6}$ Department of Radiography,

Nnamdi Azikiwe University Teaching

Hospital, Nnewi, Nigeria; ' ${ }^{D}$ ivision of

Endocrinology, Department of Internal

Medicine, Federal Medical Centre, Umuahia,

Nigeria; ${ }^{8}$ Department of Hematology,

Federal Medical Centre, Umuahia, Nigeria;

'Department of Anatomical Pathology,

University of Calabar, Calabar, Nigeria;

${ }^{10}$ Division of Nephrology, Department

of Internal Medicine, University of Benin

Teaching Hospital, Benin City, Nigeria;

"Division of Cardiology, University College

Hospital Ibadan, Ibadan, Nigeria

Correpondence: Kenneth Arinze Ohagwu Department of Internal Medicine, Federal Medical Centre, Aba Road, PMB 700 I

Umuahia, Nigeria

Tel +2348037035607

Email arysdon@yahoo.com
Abstract: The aim of the study is to validate the use of Siriraj Stroke Score (SSS) in the diagnosis of acute hemorrhagic and acute ischemic stroke in southeast Nigeria. This was a prospective study on validity of SSS in the diagnosis of stroke types in southeast Nigeria. Subjects diagnosed with stroke for whom brain computerized tomography (CT) scan was performed on admission were recruited during the study period. SSS was calculated for each subject, and the SSS diagnosis was compared with brain CT scan-based diagnosis. A total of 2,307 patients were admitted in the hospital medical wards during the study period, of whom 360 (15.6\%) were stroke patients and of these, $113(31.4 \%)$ adult subjects met the inclusion criteria. The mean age of the subjects was $66.5 \pm 2.6$ years. The mean interval between ictus and presentation was $2.5 \pm 0.4$ days. Ischemic stroke was confirmed by CT in 74 subjects; however, SSS predicted $60(81.1 \%)$ of these subjects correctly $(P<0.05)$. Hemorrhagic stroke was confirmed by CT in 39 subjects, and SSS predicted $36(92.3 \%)$ of them correctly $(P<0.05)$. In acute ischemic stroke, sensitivity, specificity, positive predictive value, negative predictive value, and accuracy of SSS were $92 \%, 94 \%, 97 \%, 86 \%$, and $93 \%$, respectively, while in patients with hemorrhagic stroke, the corresponding percentages were $94 \%, 92 \%, 86 \%, 97 \%$, and $93 \%$, respectively. SSS is not reliable enough to clinically differentiate stroke types in southeast Nigeria to warrant interventions like thrombolysis in acute ischemic stroke.

Keywords: stroke, Siriraj Stroke Score (SSS), hemorrhagic stroke, acute ischemic stroke, CT scan

\section{Introduction}

The World Health Organization defines stroke as a rapidly developing clinical syndrome of focal or global (in the case of coma) disturbance of cerebral function lasting longer than 24 hours or leading to death with no apparent cause other than vascular origin. ${ }^{1}$ Stroke is a leading cause of morbidity and mortality worldwide. ${ }^{2,3}$ Stroke incidence in Nigeria and other Sub-Saharan African countries is on the increase. ${ }^{4}$ Factors driving this transition include changes in diet, cigarette smoking, alcohol consumption, inadequate exercise, and increase in the prevalence of obesity, and also increase in other noncommunicable diseases such as hypertension and diabetes mellitus. ${ }^{5}$

Neuroimaging techniques, especially the computerized tomography (CT) scan or magnetic resonance imaging, remain the most reliable tools for diagnosing stroke types. ${ }^{6-8}$ However, these imaging modalities are not readily available in Nigeria, especially in rural communities, and when available, they are not easily affordable due to the prevailing poverty and high cost. ${ }^{2,9}$ The unavailability of CT scan in a good majority of the hospitals in Nigeria, in addition to the prohibitive cost of the 
imaging, makes the use of weighted clinical scoring systems like Siriraj Stroke Score (SSS), ${ }^{10}$ Besson Stroke Score, ${ }^{11}$ and Allen Stroke Score ${ }^{8}$ imperative in making a diagnosis of stroke types in the country. SSS is most commonly used in Nigeria, probably because it is easy to calculate by the bedside of patients.

There are limited prospective validation studies for stroke scores in Sub-Saharan African countries. In Nigeria, the three previously published prospective studies on SSS reported variable conclusions, ${ }^{9,12,13}$ thus necessitating more studies. In addition, these three prospective studies were carried out in the western and northern parts of Nigeria. There is currently no published prospective study from eastern Nigeria, prompting us to undertake this study.

\section{Method}

The study was a 2-year prospective study conducted between November 2011 and October 2013 at Federal Medical Centre, Umuahia, Abia state, southeast Nigeria. Ethical clearance was obtained from the Federal Medical Centre Ethics Committee. The hospital is a tertiary center and receives referral from other hospitals in the state and from neighboring states as well. Subjects with clinical diagnosis of stroke and aged 18 years and above, who had brain CT scan done within 14 days of onset of symptoms, were recruited. Subjects with repeat or recurrent stroke were excluded from the study and so were those who performed their CT scan investigation after 14 days from the onset of features of stroke. Also excluded from the study were subjects on anticoagulant therapy prior to the episode of stroke, those with bilateral motor weakness, those with CT scan evidence of subarachnoid hemorrhage, and patients who died or left the hospital in less than 24 hours after admission. ${ }^{2}$ An interviewer structured questionnaire was administered and relevant data were collected. These include patient's age, sex, duration of symptoms before presentation, and whether the patient is a known diabetic or hypertensive. In addition, the first recorded blood pressure from onset of the stroke, consciousness level based on Glasgow Coma Scale, presence of atheroma marker, and the presence of headache or vomiting within 2 hours of onset were documented. The clinical diagnosis of stroke type was recorded by a consultant physician and the reports of CT scan by a consultant radiologist.

The SSS was calculated using the formula: $(2.5 \times$ level of consciousness $)+(2 \times$ headache $)+(2 \times[$ vomiting $]+[0.1 \times$ diastolic blood pressure $]-12-[3 \times$ atheroma marker $]$ ). A score $<-1$ was taken to suggest infarction, a score $>+1$ was taken to suggest hemorrhage, while a score of -1 to +1
Table I Calculation of SSS

\begin{tabular}{lll}
\hline Variable & Clinical feature & Score \\
\hline Consciousness (based on & $\mathrm{I} 5$ or no alteration & $0 \times 2.5$ \\
Glasgow Coma Scale) & $9-\mathrm{I} 4$ & $\mathrm{I} \times 2.5$ \\
& $3-8$ & $2 \times 2.5$ \\
Vomiting & No & $0 \times 2$ \\
Headache (within 2 hours ) & Yes & $\mathrm{I} \times 2$ \\
& No & $0 \times 2$ \\
Diastolic blood pressure (mmHg) & Yes & $\mathrm{I} \times 2$ \\
Atheroma markers & None & $\times 0.1$ \\
& One or more & $0 \times 3$ \\
Constant & & $\mathrm{I} \times 3$ \\
\hline
\end{tabular}

Abbreviation: SSS, Siriraj Stroke Score.

was considered indeterminate. ${ }^{11}$ The SSS calculation is as shown in Table 1.

Angina pectoris, diabetes mellitus, intermittent claudication, and history of transient ischemic attack were taken as atheroma markers. ${ }^{10}$

A previous history of diabetes or a fasting plasma glucose of $126 \mathrm{mg} / \mathrm{dL}$ or more, and impaired fasting glucose defined as fasting plasma glucose of $100-125 \mathrm{mg} / \mathrm{dL}$ or a random blood glucose of $180 \mathrm{mg} / \mathrm{dL}$ or higher was classified as diabetes mellitus. ${ }^{14}$

Patients presenting with systolic blood pressure $140 \mathrm{mmHg}$ and above or diastolic blood pressure $90 \mathrm{mmHg}$ and above or who had normal blood pressure but were pharmacologically being treated for hypertension were categorized as hypertensive. ${ }^{14}$

\section{Data analysis}

Data were analyzed using statistical package for social sciences (SPSS) version 20.0 (IBM Corporation, Armonk, NY, USA).

\section{Results}

Two thousand three hundred and seven adult subjects were admitted into the medical wards during the 2-year period of the study. Three hundred and sixty subjects (15.6\%) were stroke subjects. One hundred and thirteen (31.4\%) of the 360 subjects admitted with the diagnosis of stroke satisfied the inclusion criteria for our study. The mean age of our study population was $66.5 \pm 2.6$ years. The interval from ictus (brain attack) to presentation ranged from 1 to 12 days, with a mean of $2.5 \pm 0.4$ days. Sixty-three (55.8\%) subjects presented to the hospital within 24 hours of onset of symptoms. Seventy-four $(65.5 \%)$ of the 113 subjects had ischemic stroke, while $39(34.5 \%)$ had hemorrhagic stroke. 
SSS was significantly predictive of brain infarction in $60(81.1 \%)$ ischemic stroke subjects with brain CT scan diagnosis of ischemic stroke $(P<0.05)$. In subjects with hemorrhagic stroke, SSS was also accurately predictive of intracerebral hemorrhage in $36(92.3 \%)$ subjects with hemorrhage stroke $(P<0.05)$. The SSS was indeterminate in 17 subjects ( 15 ischemic stroke subjects and 2 acute hemorrhagic stroke subjects).

Subjects were stratified on the basis of age range and sex. The incidence of ischemic and hemorrhagic stroke was more common among the age range 60-69 years; 23 (31.1\%) ischemic stroke subjects and $11(28.95 \%)$ hemorrhagic stroke subjects respectively were in this age range. There was no case of ischemic stroke in the age range of 30-39 years; however, three had hemorrhagic stroke in this age group. There were no cases of hemorrhagic stroke in the age ranges of 90-99 and 100-109 years. However, four patients and one patient in these age ranges, respectively, had acute ischemic stroke.

In stratification by sex, 47 (63.5\%) males and 27 (36.5\%) females had ischemic stroke, while $16(41.0 \%)$ males and 23 (59.0\%) females had hemorrhagic stroke. The result showed that more males had acute ischemic stroke, while more females had hemorrhagic stroke $(P<0.05)$.

Among subjects with acute ischemic stroke, 56 (75.7\%) were hypertensive, while in acute hemorrhagic stroke, $28(71.8 \%)$ were hypertensive. In addition, with regard to diabetes mellitus, 29 (39.2\%) of those with ischemic stroke, and $4(10.3 \%)$ of those with acute hemorrhagic stroke were diabetes mellitus subjects.

Among the clinical features of stroke, occurrence of headache was significantly associated with a diagnosis of cerebral hemorrhage when compared with ischemia. Other significant predictors of cerebral hemorrhage include diastolic blood pressure $>90 \mathrm{mmHg}$, presence of coma $(P<0.05)$, vomiting $(P<0.05)$, mean arterial pressure $>110 \mathrm{mmHg}(P<0.05)$, and systolic blood pressure $>180 \mathrm{mmHg}(P<0.05)$. Atheroma markers were highly predictive of cerebral ischemic stroke $(P<0.05)$ (Table 2).

Among the subjects with acute ischemic stroke, the sensitivity, specificity, positive predictive value (PPV), negative predictive value (NPV), and accuracy of SSS were $92 \%, 94 \%, 97 \%$, $86 \%$, and $93 \%$, respectively. Among the subjects with hemorrhagic stroke, the sensitivity, specificity, PPV, NPV, and accuracy of SSS were $94 \%, 92 \%, 86 \%, 97 \%$, and $93 \%$, respectively.

\section{Discussion}

This is the first prospective study on validity of SSS from the eastern region of Nigeria. The sample size in this study is
Table 2 Relevant biodata and clinical features of the subjects

\begin{tabular}{|c|c|c|c|c|}
\hline & \multicolumn{2}{|c|}{ CT scan finding } & \multirow[t]{2}{*}{ Total } & \multirow[t]{2}{*}{$P$-value } \\
\hline & Ischemia & Hemorrhage & & \\
\hline \multicolumn{5}{|l|}{ Age (years) } \\
\hline $30-39$ & $0(0 \%)$ & $3(7.7 \%)$ & $3(2.7 \%)$ & \\
\hline $40-49$ & $3(4.1 \%)$ & 7 (I7.9\%) & 10 (8.8\%) & \\
\hline $50-59$ & $13(17.6 \%)$ & $9(23.1 \%)$ & $22(19.5 \%)$ & \\
\hline $60-69$ & $23(31.1 \%)$ & II (28.1\%) & $34(30.1 \%)$ & \\
\hline 70-79 & $16(21.6 \%)$ & $4(10.3 \%)$ & $20(17.7 \%)$ & \\
\hline $80-89$ & 14 (I8.9\%) & $5(12.8 \%)$ & $19(16.8 \%)$ & \\
\hline $90-99$ & $4(5.4 \%)$ & $0(0 \%)$ & $4(3.5 \%)$ & \\
\hline $100-109$ & I (I.4\%) & $0(0 \%)$ & I (0.9\%) & \\
\hline Total & $74(100 \%)$ & $39(100 \%)$ & $113(100 \%)$ & \\
\hline \multicolumn{5}{|l|}{ Sex } \\
\hline Female & 27 (36.5\%) & $23(59 \%)$ & $50(44.2 \%)$ & 0.022 \\
\hline Male & 47 (63.5\%) & $16(41 \%)$ & $63(55.8 \%)$ & \\
\hline Total & $74(100 \%)$ & $39(100 \%)$ & $113(100 \%)$ & \\
\hline \multicolumn{5}{|l|}{ GCS } \\
\hline $3-8$ & II (I4.9\%) & 16 (4I\%) & 27 (23.9\%) & 0.002 \\
\hline $9-14$ & $6(8.1 \%)$ & $6(15.4 \%)$ & $12(10.6 \%)$ & \\
\hline 15 & $57(77 \%)$ & $17(43.6 \%)$ & 74 (65.5\%) & \\
\hline Total & $74(100 \%)$ & $39(100 \%)$ & $113(100 \%)$ & \\
\hline \multicolumn{5}{|c|}{ Hypertension } \\
\hline Present & 56 (75.7\%) & 28 (7I.8\%) & $84(74.3 \%)$ & 0.653 \\
\hline Absent & $18(24.3 \%)$ & II (28.2\%) & $29(25.7 \%)$ & \\
\hline Total & $74(100 \%)$ & $39(100 \%)$ & $113(100 \%)$ & \\
\hline \multicolumn{5}{|c|}{ Diabetes mellitus } \\
\hline Present & 29 (39.2\%) & $4(10.3 \%)$ & $33(29.2 \%)$ & 0.001 \\
\hline Absent & $45(60.8 \%)$ & 35 (89.7\%) & $80(70.8 \%)$ & \\
\hline Total & $74(100 \%)$ & $39(100 \%)$ & $113(100 \%)$ & \\
\hline \multicolumn{5}{|l|}{ Vomiting } \\
\hline Present & $10(13.5 \%)$ & 21 (53.8\%) & 31 (27.4\%) & 0.000 \\
\hline Absent & $64(86.5 \%)$ & $18(46.2 \%)$ & $82(72.6 \%)$ & \\
\hline Total & $74(100 \%)$ & $39(100 \%)$ & $113(100 \%)$ & \\
\hline \multicolumn{5}{|l|}{ Headache } \\
\hline Present & 15 (20.3\%) & $20(51.3 \%)$ & $35(31.0 \%)$ & 0.001 \\
\hline Absent & 59 (79.7\%) & $19(48.7 \%)$ & $78(69.0 \%)$ & \\
\hline Total & $74(100 \%)$ & $39(100 \%)$ & $113(100 \%)$ & \\
\hline \multicolumn{5}{|c|}{ Atheroma marker } \\
\hline Present & $44(59.5 \%)$ & $9(23.1 \%)$ & $53(46.9 \%)$ & 0.000 \\
\hline Absent & $30(40.5 \%)$ & $30(76.9 \%)$ & $60(53.1 \%)$ & \\
\hline Total & $74(100 \%)$ & $39(100 \%)$ & $113(100 \%)$ & \\
\hline \multicolumn{5}{|c|}{ Mean arterial pressure $(\mathrm{mmHg})$} \\
\hline$<70$ & $2(2.7 \%)$ & $0(0.0 \%)$ & $2(1.8 \%)$ & 0.001 \\
\hline $70-110$ & $32(43.2 \%)$ & $4(10.3 \%)$ & $36(31.8 \%)$ & \\
\hline$>110$ & $40(54.1 \%)$ & $35(89.7 \%)$ & 75 (66.4\%) & \\
\hline Total & $74(100 \%)$ & $39(100 \%)$ & $113(100 \%)$ & \\
\hline \multicolumn{5}{|c|}{ Diastolic blood pressure $(\mathrm{mmHg})$} \\
\hline$\leq 90$ & $43(58.1 \%)$ & $8(20.5 \%)$ & $5 \mathrm{I}(45.1 \%)$ & 0.000 \\
\hline$>90$ & 31 (4I.9\%) & 31 (79.5\%) & $62(54.9 \%)$ & \\
\hline Total & $74(100 \%)$ & $39(100 \%)$ & $113(100 \%)$ & \\
\hline \multicolumn{5}{|c|}{ Systolic blood pressure (mmHg) } \\
\hline$<140$ & 15 (20.3\%) & $2(5.1 \%)$ & $17(15.0 \%)$ & 0.002 \\
\hline $140-159$ & $18(24.3 \%)$ & $3(7.7 \%)$ & $21(18.6 \%)$ & \\
\hline $160-179$ & 14 (I8.9\%) & $6(15.4 \%)$ & $20(17.7 \%)$ & \\
\hline$\geq 180$ & 27 (36.5\%) & $28(71.8 \%)$ & 55 (48.7\%) & \\
\hline Total & $74(100 \%)$ & $39(100 \%)$ & $113(100 \%)$ & \\
\hline
\end{tabular}

Abbreviations: CT, computed tomography; GCS, Glasgow Coma Scale. 
larger when compared with any of the previous prospective studies emanating from Nigeria. The result showed that 360 (15.6\%) of the subjects admitted into the medical wards of the hospital during the study period had stroke. In addition, only 113 (31.4\%) of the 360 patients could afford CT scan. The low use of CT scan by the stroke subjects points to its unaffordability to the majority of the subjects. The result also showed that SSS was highly predictive of both acute ischemic stroke and acute hemorrhagic stroke, achieving PPV of $97 \%$ and $86 \%$, respectively, with an overall predictive accuracy of $93 \%$. This overall predictive accuracy is higher than the values reported in southwest Nigeria $(80 \%)^{9}$ and northeast Nigeria $(84.6 \%) .{ }^{12}$ However, the predictive accuracy observed by Salawu et $\mathrm{al}^{13}$ also from northeast Nigeria and by Connor et $\mathrm{al}^{15}$ from South Africa was much lower than that observed in this study. A reason for this in the Salawu et al ${ }^{13}$ study may be the small sample size (about half our sample size). The reason for the difference in the Connor et $\mathrm{al}^{15}$ study is not certain.

The findings in this study that $66.4 \%$ of the patients had ischemic stroke, while $33.6 \%$ of the patients had hemorrhagic stroke are in keeping with those of earlier studies on stroke in Nigeria. ${ }^{16-18}$

Among the patients with acute ischemic and hemorrhagic stroke, $56(75.7 \%)$ and $28(71.8 \%)$, respectively, had hypertension, while $29(39.2 \%)$ and $4(10.3 \%)$, respectively, had diabetes mellitus. This finding showed that hypertension is a major risk factor for both types of stroke, while diabetes mellitus is a stronger risk factor for ischemic stroke than for hemorrhagic stroke. These findings are similar to those of other prospective studies in other African countries. ${ }^{19-21}$

Headache and vomiting were found to be predictive of hemorrhagic stroke, which is in keeping with the study carried out by Kolapo et al. ${ }^{9}$ In addition, diastolic blood pressure greater than $90 \mathrm{mmHg}$ was also predictive of acute hemorrhagic stroke. Atheroma marker was predictive of acute ischemic stroke in this study, but not in the study by Kolapo et al. ${ }^{9}$ Nyandaiti and Bwala ${ }^{12}$ reported diastolic blood pressure greater than $110 \mathrm{mmHg}$ as a discriminant variable in differentiating cerebral infarction from cerebral hemorrhage, which is similar to the findings in this study.

Sixty-three (55.8\%) subjects with acute ischemic and acute hemorrhagic stroke presented within 24 hours of onset of features of stroke. The higher percentage of subjects that presented within the first 24 hours from ictus underlines the need for accurate diagnosis of the stroke type to enable the commencement of appropriate treatment with thrombolytics. However, to facilitate accurate diagnosis of stroke, CT scan should be made available at affordable cost in most hospitals in Nigeria. This need cannot be overemphasized. The management of the tertiary and secondary hospitals, and the government should make every effort to have this facility in their hospitals at affordable cost.

\section{Conclusion}

This study showed that SSS is fairly reliable in differentiating acute ischemic stroke from acute hemorrhagic stroke, but efforts should be made by the government and other agencies to make neuroimaging available and affordable in resource poor settings, as critical decisions cannot be made in acute stroke without imaging. Neuroimaging remains the gold standard in diagnosing stroke types.

\section{Limitations}

1. The sample size is relatively small. A larger sample size, preferably involving many centers, is desirable.

2. A large proportion did not have CT scan done and were thus excluded. This could have affected the result of the study.

\section{Disclosure}

The authors report no conflicts of interest in this work.

\section{References}

1. Sacco RL, Kasner SE, Broderick JP, et al. An updated definition of stroke for the 21 st century. A statement for healthcare professionals from the American Heart Association/American Stroke Association. Stroke. 2013;44:2064-2089.

2. Sherin A, Khan A, Rehman S, Shah NH, Shabbier G, Zarif M. Comparability and validity of Siriraj stroke score and Allen stroke score in differentiation of acute ischemic and haemorrhagic stroke. JPMI. 2011;25:206-216.

3. Imarhiagbe FA, Ogbeide E. Clinical-imaging dissociation in strokes in a southern Nigerian tertiary hospital: review of 123 cases. Niger J Hosp Pract. 2011;8:3-7.

4. Myles DC, Girish M, Charles PW. Accuracy of the Siriraj and Guy's hospital stroke scores in urban South Africans. Stroke. 2007;38: $62-68$.

5. Chukwuonye II, Chuku A, John C, et al. Prevalence of overweight and obesity among adult Nigerians - a systematic review. Diabetes Metab Syndr Obes. 2013;6:43-47.

6. Eze CU, Okaro AO, Ohagwu CC. Pattern of computed tomography findings in cerebrovascular accident patients in south eastern Nigeria - a retrospective study of 480 patients. Eur J Sci Res. 2009;34: 104-109

7. Khan J, Rehman A. Comparison of clinical diagnosis and computerized tomography in ascertaining type of stroke. J Ayub Med Coll Abbottabad. 2005;17:65-67.

8. Sandercock PA, Allen CM, Corston RN, Harrison MJ, Warlow CP. Clinical diagnosis of intracranial haemorrhage using Guy's hospital score. BMJ. 1985;291:1675-1677.

9. Kolapo KO, Ogun SA, Danesi MA, Osalusi BS, Odusote KA. Validation study of the Siriraj stroke score in African Nigerians and evaluation of the discriminant values of its parameters: a preliminary prospective CT scan study. Stroke. 2006;37:1997-2000. 
10. Poungavarin N, Viriyavejakul A, Kpomontric C. Siriraj-stroke and validation study to distinguish supratentorial intracerebral haemorrhage from infraction. BMJ. 1991;302:1565-1567.

11. Besson G, Robert C, Hommel M, Perret J. Is it clinically possible to distinguish nonhemorrhagic infarct from hemorhagic stroke? Stroke. 1995:26:1205-1209.

12. Nyandaiti YW, Bwala SA. Validation study of Siriraj Stroke Score in north-east Nigeria. Niger J Clin Pract. 2008;11:176-180.

13. Salawu F, Umar I, Danburam A. Comparison of two hospital stroke scores with computerized tomography in ascertaining stroke type among Nigerians. Ann Afr Med. 2009;8:14-18.

14. Chukwuonye II, Chuku A, Onyeonoro UU, Okpechi IG, Madukwe OO, Ogah OS. Prevalence of abdominal obesity in Abia State, Nigeria: results of a population-based house-to-house survey. Diabetes Metab Syndr Obes. 2013;6:285-291.

15. Connor MD, Modi G, Warlow CP. Accuracy of the Siriraj and Guy's Hospital Stroke Scores in Urban South Africans. Stroke. 2007;38: 62-68.
16. Osuntokun BO, Odeku E, Adeloye RB. Non-embolic ischemic cerebrovascular disease in Nigerians. J Neurol Sci. 1969;9:361-388.

17. Ogun SA, Ojini FI, Ogungbo B, Kolapo KO, Danesi MA. Stroke in south west Nigeria: a 10-year review. Stroke. 2005;36:1120-1122.

18. Ogun SA, Oluwole O, Fatade B, Ogunseyinde AO, Ojini FI, Odusote KA Comparison of Siriraj Stroke Score and the WHO criteria in the clinical classification of stroke subtypes. Afr J Med Med Sci. 2002;31:13-16.

19. Garbusinski JM, van der Sande MA, Bartholome EJ, et al. Stroke presentation and outcome in developing countries: a prospective study in the Gambia. Stroke. 2005;36:1388-1393.

20. Connor MD, Modi G, Warlow CP. Differences in the nature of stroke in a multiethnic urban South African population: the Johannesburg hospital strokes register. Stroke. 2009;40:355-362.

21. Sagui E, M'Baye PS, Dubecq C, et al. Ischemic and hemorrhagic strokes in Dakar, Senegal: a hospital-based study. Stroke. 2005;36: 1844-1847.
International Journal of General Medicine

\section{Publish your work in this journal}

The International Journal of General Medicine is an international, peer-reviewed open-access journal that focuses on general and internal medicine, pathogenesis, epidemiology, diagnosis, monitoring and treatment protocols. The journal is characterized by the rapid reporting of reviews, original research and clinical studies across all disease areas.

\section{Dovepress}

A key focus is the elucidation of disease processes and management protocols resulting in improved outcomes for the patient. The manuscript management system is completely online and includes a very quick and fair peer-review system. Visit http://www.dovepress.com/ testimonials.php to read real quotes from published authors.

Submit your manuscript here: http://www.dovepress.com/international-journal-of-general-medicine-journal 